\title{
MOVIMENTOS MIGRATÓRIOS E INTERNACIONALIZAÇÃO DA EDUCAÇÃO SUPERIOR
}

\author{
José Alberto Antunes de Miranda \\ PAULO FOSSATI \\ Universidade La Salle, Canoas, Rio Grande do Sul, Brasil
}

\begin{abstract}
Resumo: $O$ artigo estabelece o diálogo entre a internacionalização da educação superior e o papel da universidade a partir dos movimentos migratórios. Tem por objetivo fazer uma reflexão crítica sobre o papel da universidade brasileira e o fenômeno atual da imigração alicerçando-se nas ações de internacionalização da educação superior, no âmbito da responsabilidade social. O estudo pauta-se em uma abordagem qualitativa e quantitativa a partir de leituras bibliográficas e análise de documentos, utilizando periódicos científicos, livros e documentos legais. Os resultados apresentam uma reflexão sobre o papel da universidade como instituição com poder transformador de pessoas, pelo viés da cooperação internacional, por meio de ações sociais integrativas.
\end{abstract}

Palavras-chave: Internacionalização. Mobilidade Humana. Refugiados. Responsabilidade Social.

INTRODUÇÃO

Muitos países, assim como o Brasil, têm recebido um número bastante expressivo de imigrantes, em sua grande maioria em situação de refúgio. Segundo dados do Relatório Anual do Observatório das Migrações Internacionais - OBMigra 2019, já ultrapassam 700 mil, entre 2010 a 2018. Segundo dados do OBMigra 2019, haitianos, venezuelanos e colombianos são as três principais nacionalidades que formam o grupo de imigrantes que viviam no Brasil em 2018, sendo que os dois primeiros tiveram o maior número de carteiras de trabalho emitidas (MINISTÉRIO DA JUSTIÇA E SEGURANÇA PÚBLICA, 2019).

O fenômeno migratório não é novo. Durante séculos, milhares de pessoas deslocaram-se de sua terra de origem em busca de novos espaços para viver. Há muitos motivos para esses deslocamentos, dentre eles, questões de ensino, busca de trabalho, melhores condições de vida e dignidade, motivos econômicos e até por questões políticas. Contudo, a migração por motivo de estudo, em uma determinada localidade, não pressupõe que as pessoas irão voltar para seu local origem. Em alguns casos, elas ficam e estabelecem-se na terra de destino. 
O objetivo deste trabalho é fazer uma reflexão crítica sobreo papel da universidade brasileira e o fenômeno atual da imigração, a partir das ações de internacionalização da educação superior, no âmbito da responsabilidade social.

O estudo pauta-se em uma abordagem qualitativa e quantitativa que, segundo Gay, Mills e Airasian (2009), deve ser usada nos casos em que se deseja compreender de forma mais completa um fenômeno, utilizando as estratégias das duas abordagens. Nesta pesquisa, utilizamos o modelo QUANTI-QUALI, em que os dados quantitativos e qualitativos são coletados ao mesmo tempo e possuem igual relevância (GAY; MILLS; AIRASIAN, 2009).

Para isso, realizamos uma pesquisa bibliográfica, descrita por Leão $(2016$, p. 107) como "[...] aquela que predominantemente utiliza informações provenientes de material gráfico, sonoro ou informatizado na tentativa de resolver um problema ou adquirir conhecimento sobre um determinado assunto". Neste momento, utilizamos periódicos científicos nacionais e internacionais, nos idiomas português e inglês, além de livros. Também realizamos a busca de documental que se refere a materiais que ainda "[...] não receberam qualquer tratamento analítico, tais como: documentos oficiais, reportagens de jornal, cartas, contratos, diários, filmes, fotografias, gravações etc" (GIL, 2008, p. 57). Assim, consultamos os seguintes documentos legais: Lei no 13.445 (BRASIL, 2017); Refúgio em números, $4^{\text {a }}$ edição (ACNUR, 2018a); e Relatório de atividades (ACNUR, 2018b).

Na primeira seção, explora-se a reflexão do papel da universidade como instituição com poder transformador de pessoas, pelo viés da cooperação internacional, por meio de ações sociais integrativas, a exemplo da promoção da diversidade cultural. Apresenta-se ainda uma breve trajetória histórica das universidades em sua acolhida a estudantes em situações de mobilidade internacional, de refúgio e de fluxos migratórios. A elaboração de políticas internacionais para imigrantes, a exemplo de organismos como a UNESCO, vem ajudando as universidades a redesenhar a sua contribuição social às causas humanitárias. Neste cenário, na primeira década do século XXI, o Brasil assume o protagonismo e torna-se referência na causa dos direitos humanos e dos imigrantes.

$\mathrm{Na}$ segunda seção, aborda-se a missão das universidades brasileiras na promoção da multiculturalidade e da inclusão social desses procedentes de fluxos migratórios. Dentre os desafios a serem superados estão as diversas fronteiras culturais, o envolvimento da comunidade, a integração social, a inserção no mundo do trabalho e a inclusão e permanência deles na própria universidade. Todo este contexto exige um papel ativo das universidades, muito além de programas de extensão comunitária, para a solução de eventuais dificuldades e para o reconhecimento social desses refugiados, oriundos de diversos países, sendo venezuelanos e haitianos em maior número.

Aliar o debate sobre internacionalização da educação superior e o papel da universidade, a partir dos movimentos migratórios, é reconhecer que a internacionalização possui um importante viés transformador para os indivíduos e também para a própria universidade. 
MIRANDA, J. A. A. de ${ }_{\text {FOSSATI, P }}$

\section{REFERENCIAL TEÓRICO}

\section{A UNIVERSIDADE COMO ENTE TRANSFORMADOR DO INDIVÍDUO NO ÂMBITO DAS MIGRAÇÕES INTERNACIONAIS}

A Universidade é um espaço integrador e interdisciplinar que, por natureza, discute as relações e o ambiente social. $O$ seu processo de internacionalização também vai além das ações corriqueiramente conhecidas, como o intercâmbio e a pesquisa internacional. É intrínseco à universidade contribuir para a resolução dos problemas envolvendo a migração internacional, por meio de ações sociais integrativas, no âmbito da assimilação do outro.

O desenvolvimento de atividades por parte da universidade, que ajudem os imigrantes a se integrar à sociedade brasileira, é parte de sua função social. Esse tipo de atendimento também contribui para um conjunto de ações da internacionalização da própria instituição, em que o imigrante é convidado a contribuir para fomentar um ambiente de diversidade de culturas e opiniões, como deve ser o espaço universitário. De muitas maneiras, as instituições de ensino superior estão melhor equipadas e são mais flexíveis do que outros setores da sociedade para lidar com os imigrantes, pois já recebem estudantes internacionais. Além de possuírem uma infraestrutura bem desenvolvida no local, desde salas de aula, bibliotecas até assistência com serviços de laboratório, moradia e alimentação, contam também com outros recursos-chave e pessoal de apoio treinado.

As universidades acumulam uma larga experiência em receber estudantes internacionais ao longo de sua história. O processo de globalização, que levou a uma mobilidade ainda maior de indivíduos em busca de melhores oportunidades educacionais, trouxe novos desafios para instituições de ensino superior. Conflitos étnicos, conflitos religiosos e dificuldades econômicas têm sido os principais impulsos da migração educacional, mesmo em períodos com menores fluxos de imigrantes (STREITWIESER; MILLER-IDRISS; WIT, 2017). Esse aumento da mobilidade internacional de indivíduos vem direcionando a maior parte da agenda do ensino superior e dos governos nacionais, estimulando ações de internacionalização e resultando em cinco milhões de estudantes que atualmente cursam a universidade em outros países. Isso representa um aumento de dois milhões em relação à virada do século e é esperado um aumento para oito milhões na próxima década.

Os estudantes imigrantes em situação de refúgio, em particular, são uma pequena parcela desses números. Eles não geram receita de curto prazo, mas, sim, custos para as instituições e governos receptores, porém, isso não deve ser motivo para ignorá-los (STREITWIESER; MILLER-IDRISS; WIT, 2017). Os fluxos migratórios, dos quais os estudantes imigrantes fazem parte, abrangem milhões de pessoas em todo o mundo, motivadas a se movimentar entre países e dentro de países por diversas razões, tanto voluntárias (para o trabalho e/ou como estudantes) como involuntárias (como refugiados políticos ou econômicos). ${ }^{1}$ A Organização das Nações Unidas (ONU, 2013) estima que o número total de refugiados seja, globalmente, de 15,7 milhões, o que representa aproximadamente $7 \%$ dos migrantes internacionais em geral. No entanto, de acordo com especialistas do Alto Comissariado das Nações Unidas para Refugiados - ACNUR, apenas 1\% é capaz de acessar o ensino superior. Após um período de declínio entre 1990 e 2010, o número de refugiados tem aumentado nos últimos anos. Quase $90 \%$ desses refugiados vivem em 
áreas em desenvolvimento; $87 \%$ dos refugiados em todo o mundo residem no hemisfério sul (STREITWIESER; MILLER-IDRISS; WIT, 2017).

Propõe-se que a recepção e as ações para imigrantes em situação de vulnerabilidade nas universidades brasileiras devem ser compreendidas e trabalhadas a partir das ações de internacionalização do ensino superior mais abrangentes, pois, além do engajamento institucional, a universidade despende esforços para ajudar os imigrantes a manter e adquirir habilidades educacionais. Isso exige preparo e dedicação entre os envolvidos, pois o processo de internacionalização abrange um conjunto que identifique o enfoque e uma série de comportamentos estratégicos institucionalizados, no âmbito da educação superior, em resposta às mudanças na educação terciária no século XXI.

Fatores internos constantemente redefinem o significado institucional da internacionalização, conectam de forma abrangente a missão, os valores e as prioridades e propiciam a constante evolução desses aspectos (HUDZIK, 2011). Durante o período em que essas ações são desenvolvidas, as universidades terão um impacto significativo e contínuo na recuperação e na reconstrução desses indivíduos e no seu esforço para se integrarem à vida em sociedade em um novo país.

Como parte do processo de resposta da universidade a esse problema social, a comunidade como um todo precisa considerar não só o impacto que os imigrantes têm sobre as localidades que se encontram, mas, também, compreender quais são os impactos para os próprios imigrantes e para o mercado de trabalho, além das suas necessidades educacionais. A resposta aos fluxos de imigrantes não é, portanto, apenas uma questão de vistos, de controle de fronteiras e outras medidas restritivas. É também uma questão de responsabilidade social, na qual a educação oferecida pelas universidades tem uma importância fundamental para tentar inseri-los, da melhor forma possível, na sociedade que os está recebendo. As discussões sobre o controle ou a acomodação dos fluxos de imigrantes, a lida com os desafios de reassentamento e promoção da integração bem-sucedida de curto e longo prazo precisam incluir a educação desse contingente como um fator essencial. A universidade possui um papel primordial e tem condições de ajudar no sentido de buscar soluções para os problemas locais causados por esses deslocamentos (WIT; ALTBACH, 2015).

A partir disso, indicamos que as universidades devem ser vistas como locais essenciais de amparo ao imigrante, estando ele ou não em situação de refúgio, pois ela é capaz de responder mais rapidamente às suas necessidades com o auxílio de parcerias com entes públicos e privados. Nem sempre as instituições possuem os recursos necessários, mas podem, a partir de ações de voluntariado e de outras parcerias, ajudar esses imigrantes a se tornarem estudantes, contribuindo indiretamente para melhora da qualidade de vida desses indivíduos, facilitando sua integração ao local como um membro produtivo. Além da oferta de seminários formativos, aulas específicas ou painéis de conferências, dentre tantas outras possibilidades, a universidade precisa observar as necessidades desses imigrantes. Precisam facilitar a sua inserção na sociedade local como indivíduos que possam contribuir de forma positiva para essas comunidades.

As ações de voluntariado de estudantes e professores podem contribuir muito para o auxílio a esses indivíduos. A conscientização dos estudantes e professores universitários 
sobre a responsabilidade social da universidade, que deve ser demonstrada e validada a partir de ações concretas, envolvendo as diferentes áreas do conhecimento, pode, de alguma forma, colaborar para formação e qualificação do imigrante em situação de vulnerabilidade. Esse apoio educacional auxilia o imigrante a ser melhor inserido no espaço social onde se encontra, tornando-o um membro útil à comunidade e não mais alguém visto com desconfiança. Tanto a universidade pública quanto a privada precisam estar conscientes disso.

Morosini destaca que as conferências regionais e mundial de educação superior (CRES/CMES), coordenadas pela UNESCO, embora não possuam um caráter determinante, vêm ocupando um espaço de significativa influência na elaboração de políticas nacionais e institucionais. Em recente evento da UNESCO, no âmbito latino americano, foi destacado o papel da universidade para resolução dos problemas de desenvolvimento sustentável, integração solidária e de diálogo com a sociedade a partir de suas dificuldades locais. Dentre alguns pontos destacados, é importante definir e adaptar indicadores de produção autônomos com forte orientação ante as necessidades da região, em diálogo com a sociedade, tendo em conta a pertinência da produção e as particularidades de cada região. Da mesma forma, salienta-se a necessidade de maximizar o uso eficiente de recursos, o estímulo à produção científica, tecnológica e inovativa e o desenvolvimento de vínculos mais fortes com as demandas sociais; além de ampliar as políticas e ações afirmativas de inclusão, de gênero, etnias e grupos culturais de pessoas de diversas condições, como imigrantese outras populações em condições de vulnerabilidade (MOROSINI, 2017). Nesse sentido, a relação entre a internacionalização das universidades e as dinâmicas migratórias surge como central para sintonizar os problemas migratórios com a realidade do ensino superior. Trabalhar definições de migração mais amplas e menos restritivas é fundamental dentro das universidades.

As definições que não especificam o tipo de sujeito da imigração, mas, sim, os trajetos em que elas ocorrem, podem nos ajudar a reconhecer a realidade pela qual muitos estudantes passam, que se aproxima com suas especificidades. Exemplificando, há vários tipos de imigrantes com necessidades e expectativas diversas, aqueles em situação de refúgio são diferentes dos que vêm para um intercâmbio acadêmico ou ainda dos que chegam em busca de trabalho. É importante também perceber os potenciais que os fluxos estudantis têm na criação de uma trajetória migratória.

A vinda para o Brasil pode não ter um fim em si mesma. Ela precisa ser colocada em perspectiva, tendo em vista as intenções e expectativas dos imigrantes, quaisquer sejam elas. Alguns podem ter a intenção de emigrar para outros países e não somente ficar no Brasil, outros podem desejar passar um tempo por aqui, conquistando novos conhecimentos para, quando possível, retornar a seus países de origem, contribuindo assim para o desenvolvimento deles (LAJUS, 2019). Portanto, é preciso destacar a complexidade dos motivos de cada um para imigrar. Inicialmente, as migrações no Brasil eram vistas apenas pelo seu caráter compulsório e os imigrantes como sujeitos expropriados, expulsos de uma localidade para outra, peregrinando em busca de trabalho e melhores condições econômicas. Mas a migração também deve ser vista como uma oportunidade para a conquista de novos conhecimentos aos quais eles não teriam acesso em seus países de origem, portanto as universidades brasileiras devem estar preparadas para oferecer isso, tornando-se centros de difusão de conhecimento na América Latina. 
Durante o primeiro decênio do século XXI, a recepção de imigrantes caracterizouse pela forte exigência de qualificação profissional. O Brasil sofria com a insuficiência de mão de obra qualificada localmente. Nesse período, para dar conta desses profissionais qualificados, demandados pela economia transnacional, destacou-se a vinda de norteamericanos, japoneses, ingleses e outros imigrantes reconhecidos pela alta qualificação de mão de obra. Nesses países, por sua vez, ocorria um movimento de exportação do excedente de mão de obra qualificada para os países emergentes. Complementando o quadro desse movimento, veio a imigração de portugueses, espanhóis e italianos, cujos países de origem encontravam-se em estagnação econômica e em sucessivas crises políticas. Para estes últimos, o Brasil acenava com seus indicadores de expansão econômica, principalmente a partir de 2008.

Importante salientar que a dinâmica econômica é, portanto, um fator de forte capacidade atrativa de pessoas e responde por uma parcela substancial de imigrantes que se deslocaram motivados por tais perspectivas (MARTINE, 1984, 1987; LEE, 1980). As regiões mais desenvolvidas do ponto de vista econômico apresentam maior atratividade aos imigrantes, que vêm, na maioria das vezes, em busca de trabalho e melhores condições socioeconômicas, optando pela permanência em regiões/cidades de melhor infraestrutura e de maior oferta de serviços. Essa perspectiva clássica da dinâmica populacional foi observada desde os estudos da última metade do século XX (TODARO, 1980; WOOD, 1982) e ainda se mantém como forte fenômeno, o que explica a dinâmica migratória no Brasil na primeira década do século XXI (FRAGUGLIA et al., 2007; FRAGUGLIA \& MENEZES FILHO, 2012).

Estabelecia-se assim um campo de oferta propício para imigrantes desejáveis para a composição de mão de obra qualificada no território nacional, em prol da elevação do status do Brasil junto ao capitalismo globalizado. O Brasil torna-se, então, campo de rotação migratória, consoante à ordem internacional impressa à divisão do trabalho (UEBEL; RÜCKERT, 2017). Em meio aos anos de maior imigração, nos primeiros quinze anos do século XXI, a questão da migração internacional passou a ser capitaneada pelo governo brasileiro em busca do reconhecimento político internacional.

A partir de 2009, o governo brasileiro assume em seus discursos de política externa a questão dos direitos humanos dos imigrantes. Critica, por um lado, as restrições de caráter securitista da União Europeia a imigrantes latino-americanos. Por outro, sinaliza portas abertas no Brasil a imigrantes em situação que exige a aplicação de direitos humanos no tratamento da migração internacional. Corrobora esse fato que em 2009 tenha ocorrido a anistia do maior contingente de imigrantes após a redemocratização do país. Mediante o uso do instituto da anistia, através da Lei 11.961/2009 - Lei de Anistia ao Imigrante, houve a regularização da situação de estrangeiros que entraram no Brasil de forma irregular até 01/02/2009. Em números, de acordo com Reis (2011), em 2009 foram regularizados mais de 43 mil indocumentados, sendo $22 \%$ a mais do que número contemplado em 1998, através da Lei 9.474 (Brasil, 1997). Consoante à política governamental de apoio aos imigrantes mais vulneráveis foram contemplados 17 mil bolivianos e mais de 4 mil paraguaios do total dos imigrantes indocumentados beneficiados em 2009. 
Dadas as condições econômicas favoráveis e a visibilidade internacional, o Brasil torna-se ponto de destino para os latino-americanos dos países vizinhos em busca de melhores condições de vida, fato demonstrado nos números de 2014. Por não encontrarem condições de vida adequadas em seus próprios países de origem, nos primeiros quinze anos do século XXI, houve uma intensa migração para o Brasil de latinoamericanos. Salvo o Paraguai, que se recuperava economicamente, entre 2010 e 2014, a imigração para o Brasil tornou-se para uma expressiva parcela de imigrantes a melhor opção.

Contudo, nesse novo grupo de imigrantes não foi a qualificação profissional o fator determinante, embora tenha predominado, inicialmente, entre aqueles vindos da Argentina e do Uruguai. Essa migração internacional, em especial de latino-americanos, para um país em desenvolvimento como o Brasil, em busca de melhoria de vida, teve como característica o fortalecimento de redes de indivíduos, formando coletivos que protegiam os participantes e incentivavam a vinda de novos imigrantes, o que propiciava - gradativo crescimento do contingente populacional imigratório. A diferença de situações entre os imigrantes pode ser exemplificada pela peculiar condição dos bolivianos que se estabeleceram no Brasil, com a constatação de que muitos se encontravam em situações precárias, em condições análogas ao trabalho escravo (MIRANDA; MISTURA, 2018).

Até $\mathrm{o}$ ano de 2015, existiam cerca de 232 milhões de pessoas vivendo fora de seu país de origem, ou seja, $3,2 \%$ da população mundial, segundo dados da Organização Internacional para Migrações (OIM). Segundo o Alto Comissariado Das Nações Unidas Para os Refugiados (ACNUR), cerca de 60 milhões de pessoas são vítimas de deslocamento forçado, das quais 20 milhões são refugiados (SERRICELLA, 2016). Segundo Castles (2007), a migração contemporânea é um processo social que possui suas próprias dinâmicas. Neste sentido, a globalização e a intensificação do movimento migratório com suas dinâmicas culturais e econômicas provocaram a diversidade desses fluxos migratórios.

\section{A INTERNACIONALIZAÇÃO DA UNIVERSIDADE COMO AMBIENTE PROMOTOR DA INCLUSÃO}

Dentro da Universidade, a capacidade de resposta cultural, também conhecida como orientação cultural, é uma habilidade do facilitador de honrar a cultura e as experiências de um aluno, a fim de aprimorar seu aprendizado. Essa capacidade de resposta cultural, por sua vez, fornece a todos os alunos acesso a instruções afetivas e recursos adequados para o aprendizado. Isso requer responsividade individual e organizacional (KILLICK, 2015).

Responsabilidade cultural é a capacidade de aprender e se relacionar respeitosamente com pessoas de sua própria cultura, bem como com pessoas de outras culturas. Inclui a adequação de comportamentos pessoais e da organização com base no que se aprende. Assim, o desenvolvimento dos imigrantes, enquanto alunos, necessita que suas experiências educacionais sejam moldadas através das lentes da orientação cultural, respeitando sua cultura nativa e inserindo-os na cultura local, num intercâmbio de saberes e culturas. A universidade deve estar orientada à inclusão, dedicada a aprender sobre as mais diversas culturas e a pensar criticamente sobre experiências entre nacionais e internacionais, que podem ajudar a preservar as identidades dos estudantes, porém possibilitando o diálogo e as trocas entre eles, sejam nacionais ou estrangeiros. Isso 
dependerá da capacidade dos educadores brasileiros de oferecer aos alunos, tanto aos nacionais quanto aos estrangeiros, as orientações relacionadas à importância da diversidade e do intercâmbio cultural para seu crescimento pessoal e profissional em um mundo globalizado (BRUCE; LUEKER; WICK, 2019).

As experiências dos imigrantes variam de acordo com suas situações de origem e suas experiências de vida. Muitos estudantes estrangeiros chegam às universidades brasileiras cheios de expectativas que nem sempre são correspondidas, especialmente os que chegam em situação de vulnerabilidade social ou refúgio. Muitas vezes esses imigrantes não são incluídos na universidade como os outros alunos estrangeiros que vêm em situação normal de intercâmbio, pois são tratados como algo à parte do contexto universitário, ficando afastados dos alunos nacionais, sem conseguirem se integrar à vida acadêmica universitária e nem ao menos tendo a oportunidade de fazê-lo (ELLIOTT, 2019).

Fronteiras não são simplesmente limites territoriais e de diferentes culturas. São algo além disso, são construções abstratas complexas que representam desejos muito humanos, como o desejo de sentir-se em casa e de se associar a pessoas que compartilham signos culturais comuns, o desejo de uma classe dominante de permanecer no poder, o desejo de valorização de determinado grupo social que vem do senso de patriotismo, de orgulho nacional, ou o desejo de secularidade, da perpetuação da tradição e da segurança que isso traz em um mundo tão confuso, cada vez mais difuso e perigoso (ELLIOTT, 2019). À medida que nos acostumamos às fronteiras, essas complexidades e abstrações são fáceis de se ignorar, tornando o imaginado algo concreto, definido, definitivo. Como universidade, devemos ajudar migrantes e nacionais a compreenderem essas questões, melhorando o seu entendimento sobre as relações e interações humanas que estão por trás das próprias ações de internacionalização da universidade.

A aprendizagem intercultural pressupõe o enfrentamento e a superação das fronteiras culturais entre o "eu e os outros", para que todos possam ser compreendidos e se compreenderem. A estrutura e o currículo dos cursos superiores devem presumir e buscar auxiliar o aluno estrangeiro imigrante, em qualquer situação de choque cultural (inevitável), ajudando-o a vencer suas dificuldades, que podem aparecer durante e também depois da experiência universitária. A universidade ajuda a promover essa experiência intercultural por meio do conhecimento que é compartilhado em seu interior entre estudantes estrangeiros e nacionais (WHALEN, 2019).

O Relatório de 2018 do Comissário das Nações Unidas para Refugiados (ACNUR) observou que estamos testemunhando os níveis mais altos de deslocamento já registrados. Um número sem precedentes de 68,5 milhões de pessoas em todo o mundo que foram obrigadas a sair de casa. Entre elas, estão quase 25,4 milhões de refugiados, dos quais mais da metade tem menos de 18 anos. As pessoas deslocadas correspondem aproximadamente às populações combinadas dos dois estados mais populosos dos EUA: Califórnia e Texas (cerca de 68,5 milhões).

A taxa de crescimento é, de acordo com o mesmo relatório, surpreendente, ou seja, quase uma pessoa é forçada a deslocar-se a cada dois segundos como resultado de conflito ou perseguição (WOOLF, 2019). Porém, muitos são impedidos, privados de sua mobilidade pela extrema pobreza ou por força política. Para outros, a mobilidade 
representa a perda traumática de seu lar e o exílio. Para uma pequena parcela, a elite privilegiada, a mobilidade possibilita uma jornada rumo a coisas positivas, como educação, aventura, prazer e esclarecimento (WOOLF, 2019).

A experiência de estudos no exterior já foi definida por três estágios: num primeiro momento pelo sentimento de se estar totalmente perdido, no segundo, a sensação de se estar verdadeiramente imerso na nova cultura, muitas vezes abdicando de traços de sua cultura original, para depois, no terceiro, sentir-se totalmente inserido em uma nova comunidade. Para alguns estudantes, o processo poderia até parecer meio traumático. No entanto, atualmente, com a conectividade constante e com a troca de informações globais imediatas que são oferecidas pela tecnologia de hoje, o estudo no exterior tornouse um evento de viagem mais agradável e bem mais facilitado para um aluno estrangeiro em situação normal de um intercâmbio. As experiências são vividas de forma mais natural, sem alterar tanto a vida dos estudantes, já que eles podem manter sua bagagem cultural originária.

Já para um imigrante em situação de vulnerabilidade, a migração, muitas vezes forçada, representa uma alteração completa de vida. Ele chega com uma expectativa de inserção na nova sociedade que o recebe, o que pode não acontecer. Além de ser capaz de contornar o desconforto do desconhecido, a solidão, a discriminação e muitas vezes a rejeição do meio que deveria acolhê-lo, ele precisa lidar com as barreiras culturais que impedem o desenvolvimento de uma conexão mais profunda com olocal que deveria apoiá-lo e atender às suas necessidades sociais. No entanto, quando o imigrante tem a oportunidade de contornar essas barreiras e tornar-se um membro da comunidade, ele se envolve totalmente em sua dinâmica. Então, e somente então, o estrangeiro pode se tornar parte da comunidade e não apenas um mero espectador (ORTEGA, 2018).

Nesse sentido, observamos que desenvolver capital social e uma comunidade forte e saudável é um processo multifacetado e de longo prazo. A universidade, com o seu processo de internacionalização, desempenha importante papel ao auxiliar o estudante estrangeiro, seja imigrante ou não, encorajando-o a estabelecer relacionamentos que o envolva na comunidade, contribuindo para o desenvolvimento da mesma. Ações voluntárias desenvolvidas por estudantes nacionais e/ou estrangeiros ajudam a manter uma conexão mais profunda com suas comunidades por meio de serviços prestados.

O benefício do serviço social voluntário é poder se conectar com a comunidade. Além do projeto específico em questão, os envolvidos têm a oportunidade de desenvolver relacionamentos com pessoas que eles não teriam necessariamente encontrado no ambiente habitual de estudo, como outros voluntários, beneficiários e líderes comunitários. Por meio do voluntariado e das ações promovidas pela universidade no contexto do processo de internacionalização da educação superior, os envolvidos podem ter uma compreensão mais profunda da situação política, econômica e social que estão vivendo, assim como das situações locais e das lutas para enfrentá-las. Essa compreensão mais global, essa troca intercultural é benéfica tanto ao estudante estrangeiro quanto à comunidade assistida.

Os sistemas de ensino superior têm um papel fundamental a desempenhar para provocar uma mudança positiva tanto no campo social como na economia. Economicamente, a universidade cria mão de obra qualificada e os seus centros de pesquisa são responsáveis pelas inovações, pela disseminação do conhecimento e pela evolução tecnológica do país. Socialmente, as universidades fomentam benefícios 
públicos mais amplos, através da formação de cidadãos mais críticos, sociedades mais tolerantes, comunidades mais participativas, que podem trabalhar por melhores condições de vida para toda a coletividade. No entanto, é necessário olhar para as universidades em seus contextos espaciais e locacionais, ou seja, inseridas no espaço sociocultural dos Estados-Nação das quais fazem parte. O que se defende aqui, em nível nacional, é que as universidades são importantes, não apenas para o desenvolvimento econômico local e nacional, mas também para a construção de um projeto de nação e como o país vai ser visto fora de suas fronteiras, internacionalmente. Universidades e institutos de pesquisa podem desempenhar um papel primordial nos sistemas de inovação e na formação do capital humano qualificado em nível local. Exemplificando, as chamadas cidades universitárias amplificam sua importância ao estabelecer o desenvolvimento da economia da cidade e da região em que estão localizadas. $\mathrm{O}$ imigrante pode também contribuir, especialmente quando o seu conhecimento intrínseco pode ser aproveitado localmente.

Historicamente, há um forte reconhecimento de que as universidades desempenham um papel importante no processo de construção da identidade da nação. Em outras palavras, há expectativas de que as universidades devam ser guardiãs e geradoras da "cultura nacional" - particularmente, mas não somente, através das humanidades, como as línguas, a história e as artes - e que também podem contribuir para a valorização e integração das culturas nacional e estrangeira. Espera-se que as comunidades universitárias promovam a estabilidade política através da formação de cidadãos que trabalhem pelo fortalecimento de uma imagem positiva dos Estados-Nação, através da sua contribuição para a construção e reconstrução de identidades locais, nacionais e globais. Por outro lado, deseja-se também que, reconhecendo as diferenças e promovendo a diversidade, elas possam trabalhar também pela integração e cooperação intercultural. Exatamente por serem abertas ao fluxo de novas ideias e por prover espaços para se contestar as estruturas sociais, políticas e econômicas existentes e emergentes, as universidades desempenham um papel particularmente importante na contemporaneidade (BEALL, 2016). Mas, a universidade tem, segundo o autor, um papel ainda mais relevante, o de mediar os inúmeros problemas e conflitos locais causados ou que estejam intrinsecamente relacionados aos globais, como a questão da imigração.

A contribuição das universidades para o desenvolvimento local e regional não é um fenômeno novo: há séculos que as universidades têm uma relação profunda $e$ dinâmica com a vida econômica, social e cultural das cidades em que se baseiam. Há alguns anos, a OCDE, o Banco Mundial e outras agências internacionais reconhecem e promovem a ideia de que as universidades desempenham um amplo leque de funções, em nível local e regional, por meio de educação, pesquisa e atividades relacionadas à cultura, com ênfase particular em sua contribuição para o desenvolvimento econômico (OECD, 2007).

No Brasil, em particular, os governos municipais, estaduais e mesmo o federal ainda têm dificuldades em ver as universidades como essenciais para os sistemas de inovação econômica e para o próprio crescimento socioeconômico das comunidades. O ensino e a aprendizagem habilitam o capital humano, oferecendo à sociedade graduados altamente qualificados, que são reconhecidos como insumos fundamentais para o desenvolvimento 
de determinada localidade. Os imigrantes, independentemente de sua situação ao chegar, precisam ser vistos como agentes potenciais de transformação positiva para o local de destino, pois muitos trazem consigo práticas e conhecimentos de suas regiões de origem que podem contribuir para criação de práticas inovadoras para o novo meio em que se encontram. O imigrante precisa ser visto pelas universidades, entes públicos e pela sociedade que o recebe como um potencial contribuidor para a expansão da economia local e não como um usurpador ou degradador, ou seja, como um potencial risco social.

Um fato novo ocorrido no país nesse período, decorrente de nova configuração do poder internacional-transnacional do segundo pós-guerra, é que o Brasil passou a receber estrangeiros também na condição de refugiados e apátridas. No período de 1947 a 1953, já eram identificados os outros, além dos já conhecidos portugueses, espanhóis, italianos, alemães ou japoneses, de períodos históricos anteriores. Em termos jurídicos, a entrada de estrangeiros como refugiados no país, a partir de 1947, decorre da participação do Brasil na Organização Internacional de Refugiados - OIR (1947), posteriormente recriado como Alto Comissariado das Nações Unidas para os Refugiados - ACNUR (1950), com a subsequente edição do Estatuto dos Refugiados (1951) (MENEZES, 2018).

Durante a maior parte do período da ditadura não foi preciso revisar e sistematizar a legislação infraconstitucional sobre o imigrante, ainda anterior da Constituição de 1946. O apelo ao civismo moral popular e a coerção policial do Estado eram suficientes para garantir a aceitação dos atos e resoluções que administravam o diminuto contingente de imigrantes. O potencial de grande nocividade à ordem pública e interesses nacionais eram, nesse tempo, o marco regulatório para o tratamento ao estrangeiro. Para Ana Paula Amaral e Luiz Rosado Costa, com o Estatuto do Estrangeiro, o imigrante irregular passou a ser tratado juridicamente como um agente potencialmente subversivo, que exigia permanente controle e vigilância do Estado. Para tanto, cabia à Polícia Federal as atribuições de recepção ao imigrante, conjugadas com àquelas de repressão à criminalidade transnacional. Além do modelo policial, o Estatuto propiciava que o tratamento ao imigrante tivesse novamente ampla discricionariedade por parte das autoridades administrativas para disponibilização de vistos, permanência e naturalização de estrangeiros (AMARAL; COSTA, 2017).

No mesmo sentido, o Estatuto vedava a regularização de situações migratórias irregulares (salvo com anistia concedida em lei), obrigando o irregular à clandestinidade, que o deixava em extrema vulnerabilidade sócio-jurídica. Dessa forma, os procedimentos administrativos de recepção, permanência e trabalho caracterizaram o Brasil como um dos países mais restritivos quanto à imigração de estrangeiros (PATARRA, 2005). Contudo, mesmo com o resultado dessa política restritiva, o contingente de imigrantes recebidos na primeira quinzena do século XXI aumentou a ponto de ser comparado com aquele da migração em massa ocorrida nos fins do Império e inícios da República. Apesar das ambiguidades, institucionais e sociais no tratamento ao imigrante, o Brasil tornou-se polo de atração no processo de imigração global nos inícios do século XXI. As universidades, com isso, são pela primeira vez chamadas a contribuir para resolução dos problemas advindos dessa nova conjuntura. 
Gráfico 1: Imigrantes por país de origem

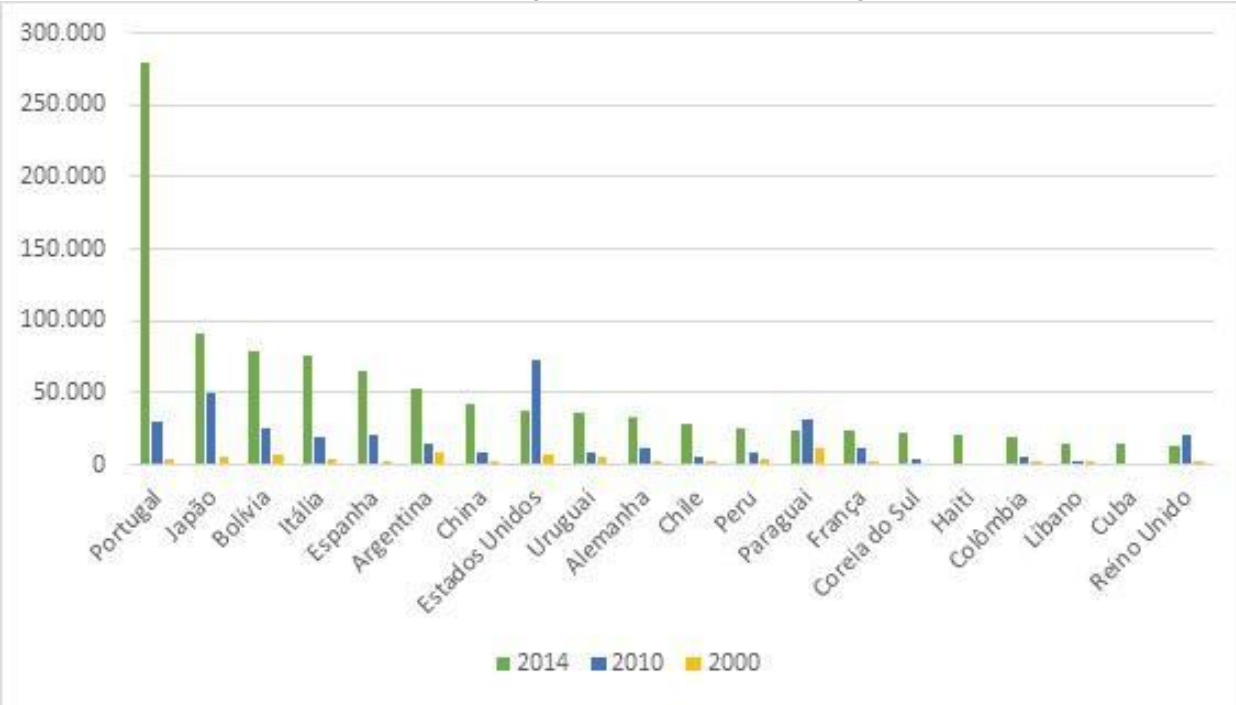

Fonte: Uebel e Rückert (2017, s/p).

Conforme demonstrado pelo gráfico acima o maior número de imigrantes residentes no país até 2014 ainda era de portugueses, muito em função do Acordo de Amizade entre Brasil e Portugal. O quadro acima já registrava a entrada constante de haitianos, mas ainda não registrava a de venezuelanos que, a partir de 2017, torna-se um problema de grande proporção para o Brasil.

No texto da Lei da Migração, as diferenças entre nacionais e imigrantes diminuem significativamente. Ao mesmo tempo em que salvaguarda o princípio de isonomia do Artigo 5. ${ }^{\circ}$ da Constituição de 1988, ao afirmar que: "Todos são iguais perante a lei, sem distinção de qualquer natureza, garantindo-se aos brasileiros e aos estrangeiros residentes no País a inviolabilidade do direito à vida, à liberdade, à igualdade, à segurança e à propriedade [...]" (BRASIL, 1988). Revela-se assim como um dispositivo normativo correspondente ao espírito das sociedades plurais e democráticas no contexto geopolítico dos Estados-Nação a partir dos fins do século XX.

Corrobora esse espírito de interdependência entre os Estados nacionais a exposição sobre os princípios e garantias contidos na Lei 13.445 (BRASIL, 2017). A política de migração passa a ser governada pelos princípios e diretrizes ali expostos, assentados nos direitos humanos, no repúdio à discriminação, na não criminalização da migração, na acolhida humanitária, no acesso a políticas públicas e no repúdio à expulsão ou deportação coletivas, entre outros. 


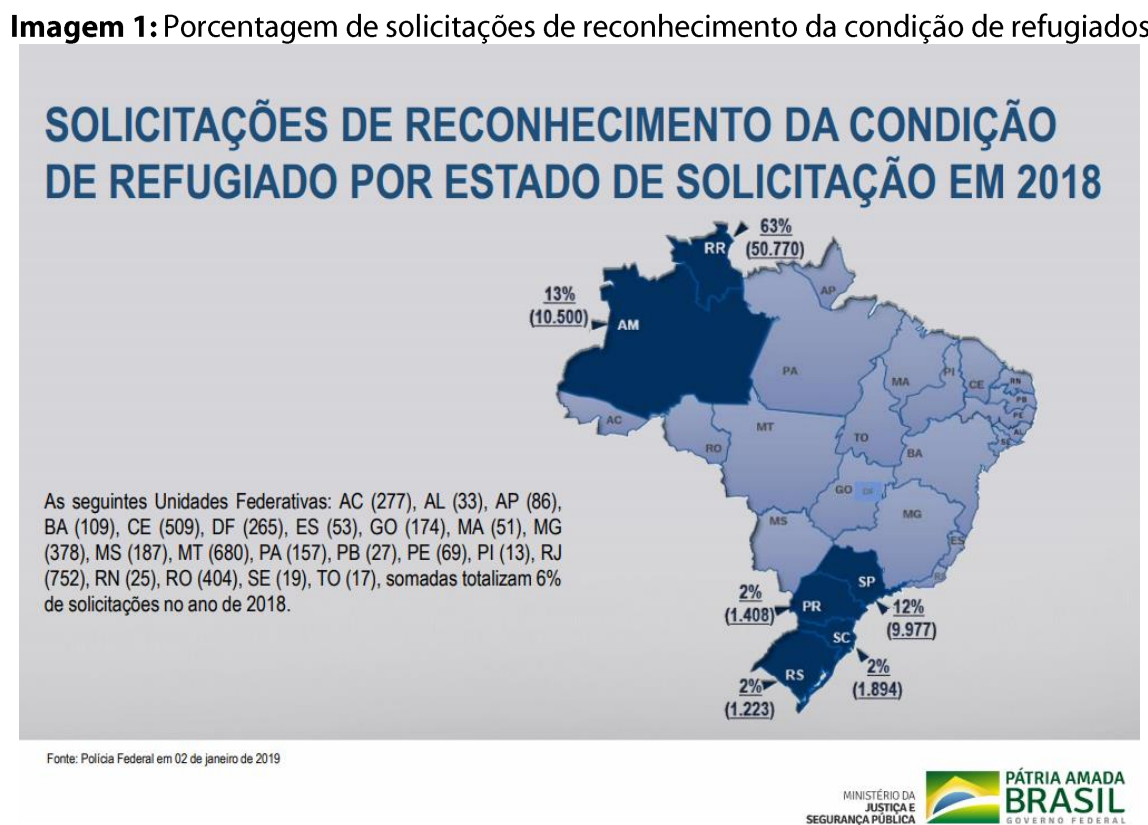

Fonte: ACNUR (2018a).

A imagem acima indica a disparidade de solicitações provindas de Roraima, estado da federação que, a partir da crise de instabilidade política e econômica da Venezuela, recebeu uma onda de imigração humanitária, precisando inclusive de grande ajuda do governo federal. Interessante observar que os estados do Sudeste, como São Paulo, e do Sul, como Paraná, Santa Catarina e Rio Grande do Sul, possuem também os mais altos números de solicitações.

Gráfico 2: Solicitações de reconhecimento da condição de refugiado por país de origem

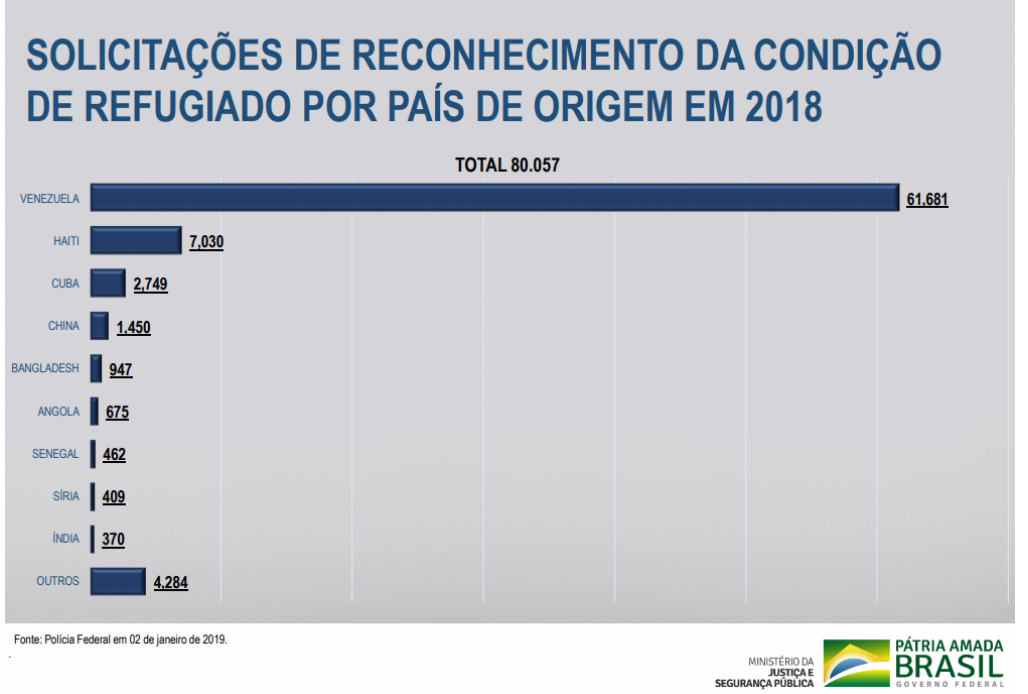

Fonte: ACNUR (2018a). 
O gráfico acima já indica, a partir de 2019, um salto de solicitações provindas da Venezuela em comparação ao segundo país, que ainda tem grande número de solicitações, o Haiti. A presença do Brasil nas forças de paz no Haiti, em função do furacão de 2010, criou uma nova rota de migração haitiana para o Brasil. Conforme os números apresentados por Baeninger e Peres (2017), a partir de registros do SINCRE, de 2010 a 2015, o número de haitianos alcançou a casa de 85.079 imigrantes, sendo $28.866 \mathrm{com}$ visto humanitário, além de 44.361 imigrantes com registro inicial em postos de fronteira terrestre. Os haitianos se constituíram assim como o grupo de migração internacional que mais ascendeu até 2015 ao território brasileiro (BAENINGER; PERES, 2017).

Gráfico 3: Perfil das pessoas refugiadas reconhecidas em 2018

\section{PERFIL DAS PESSOAS REFUGIADAS RECONHECIDAS EM 2018}
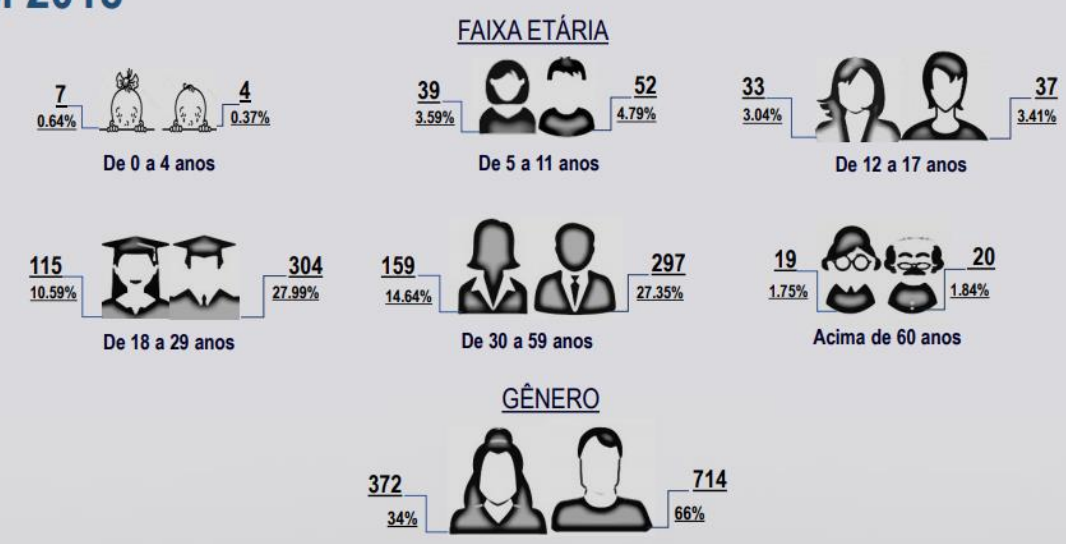

*AS INFORMAÇõES COMPREENDEM A SOMA DOS REFUGIADOS RECONHECIDOS PELO PROCESSO DE ELEGIBILIDADE E OS PEDIDOS DE EXTENSÃO DOS EFEITOS DA CONDIÇÃO DE REFUGIADO.

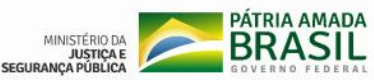

Fonte: ACNUR (2018a).

O gráfico acima nos dá uma ideia do percentual de imigrantes em situação de refúgio com ensino superior e do potencial de imigrantes que poderão ascender ao ensino superior no Brasil, na faixa etária de 12 a 17 anos e ainda de 30 a 59, sendo, na maioria, homens. Muitas universidades brasileiras já estão atendendo a essa realidade a partir de ações específicas, inclusive com parcerias com associações locais e/ou com agências internacionais como a ONU. A Cátedra Sérgio Vieira de Mello é um exemplo. 
Gráfico 4 e 5: Refugiados no Ensino Superior - Cátedra Sérgio Vieira de Mello (CSVM) implementada pelo ACNUR em 2003
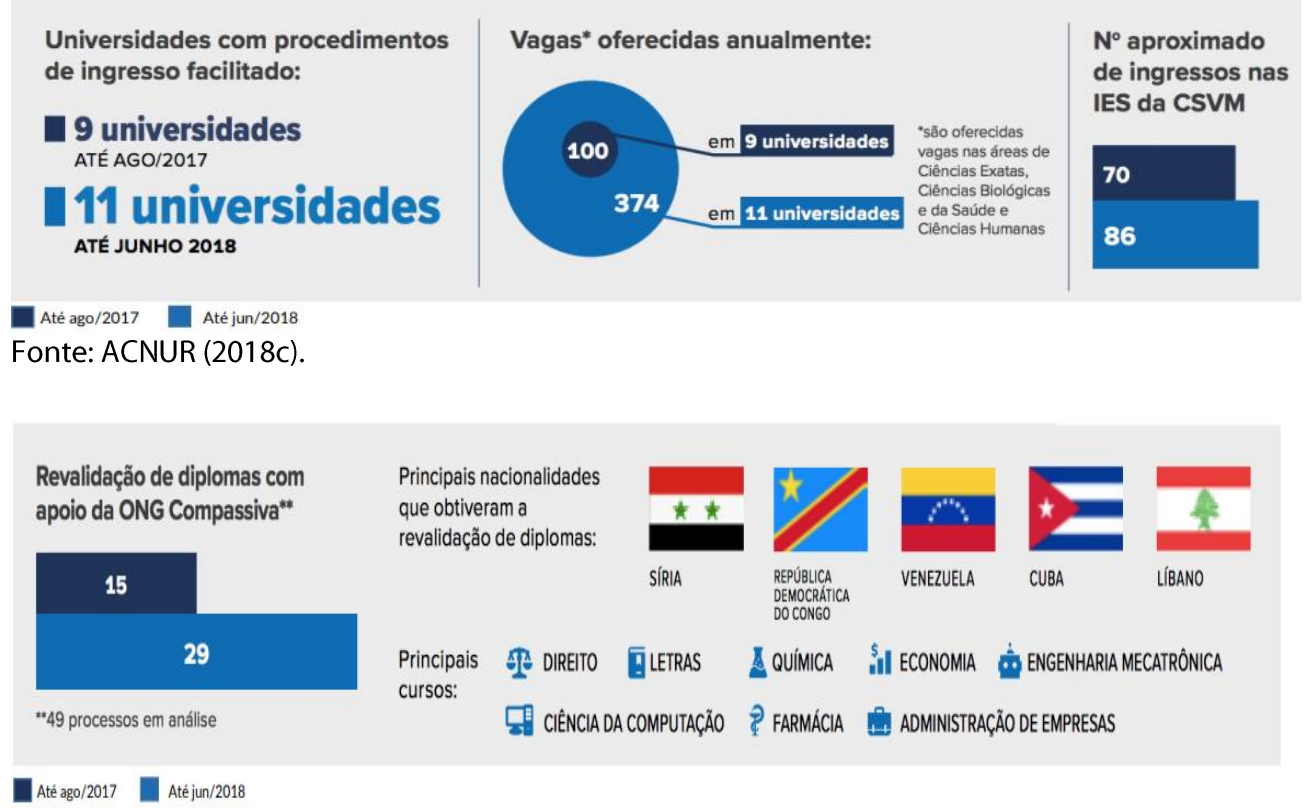

Fonte: ACNUR (2018c).

É importante observar que, a partir dos gráficos acima, até 2018 apenas 11 universidades brasileiras faziam parte do programa, entre públicas e privadas, e continham programas institucionalizados de inserção dessesimigrantes em suas comunidades. Também são apresentados o número de revalidações de diplomas solicitados por países e cursos.

Gráfico 6: Tipo de ações de extensão comunitária promovida pelas universidades brasileiras pertencentes a Cátedra Sérgio Vieira de Melo.

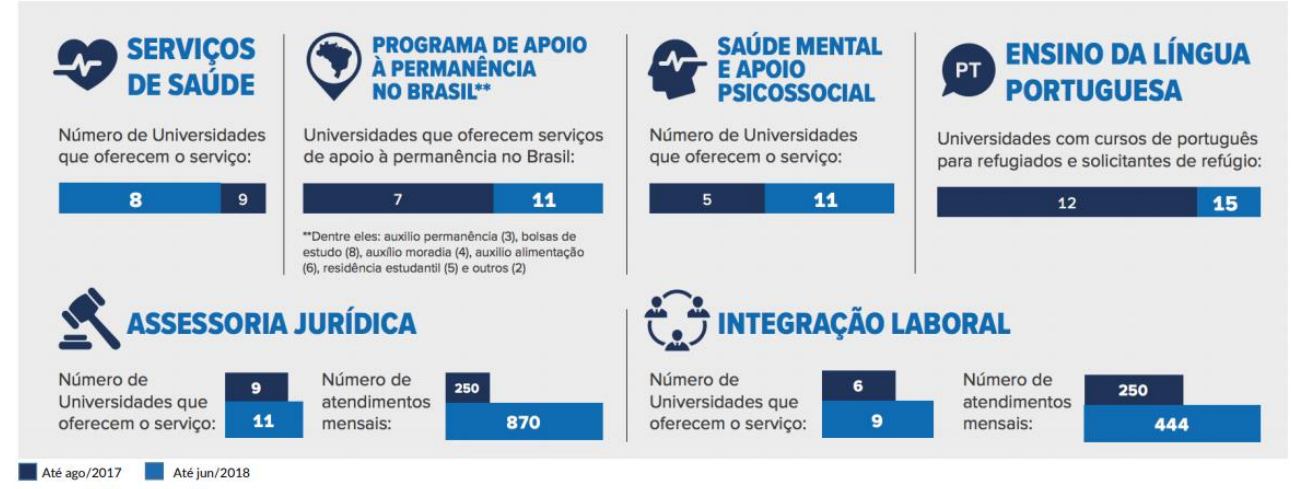

Fonte: ACNUR (2018c). 
Gráfico 7: Tipo de ações de ensino que estão sendo oferecidas pelas universidades brasileiras pertencentes a Cátedra Sérgio Vieira de Melo
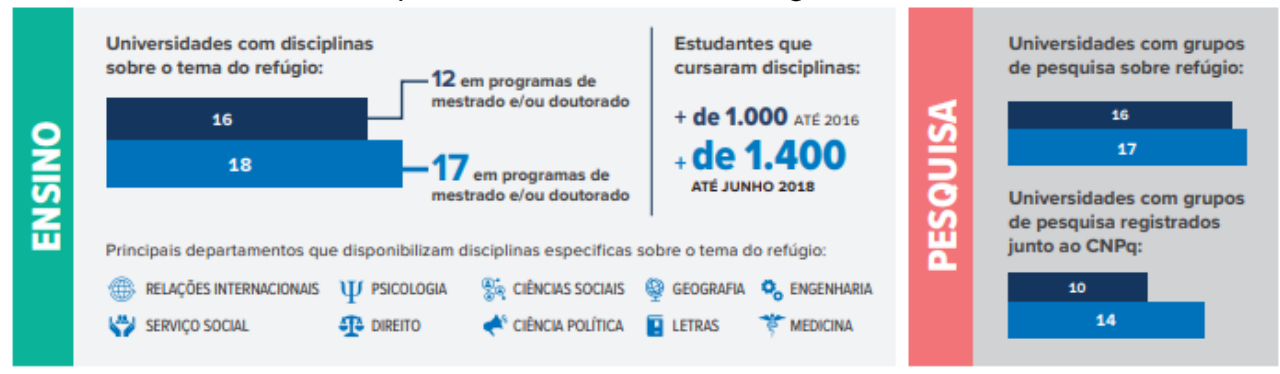

Fonte: ACNUR (2018c).

Os gráficos acima indicam as ações de ensino desenvolvidas, no âmbito das universidades brasileiras, que problematizam as discussões sobre o tema refúgio, contribuindo assim para as ações de internacionalização de seus currículos.

Atualmente, há 22 universidades no Brasil conveniadas com a ACNUR, como a Fundação Casa Rui Barbosa, as Pontíficias Universidades Católicas, como a do Rio de Janeiro, de São Paulo, de Minas Gerais, a Universidade do Estados do Rio de Janeiro, a Universidade Católica de Santos e várias outras, públicas e privadas, que se encontram listadas no site da ACNUR do Brasil e que desenvolvem algum tipo de recepção a refugiados que não possuem documentação (ACNUR BRASIL, 2018c)

Com relação às vantagens para as universidades em desenvolverem esse tipo de ações, pode-se destacar que, por serem instituições que contribuem significativamente para o desenvolvimento do local onde estão baseadas, acabam tornando esses centros urbanos mais atrativos. Cada vez mais, as universidades têm assumido o seu papel de extensão, trabalhando para assumir sua responsabilidade social, cultural e intelectual na localidade em que está inserida. Algumas universidades também levam tão a sério a sua responsabilidade pelo desenvolvimento da comunidade como parte de sua missão estratégica (extensão universitária), que se engajam em uma ampla gama de iniciativas comunitárias, desde planos de desenvolvimento econômico em colaboração com as comunidades locais, até o amplo apoio a escolas locais e a prestação de vários de serviços necessários, como encaminhamento de documentos, assistência à saúde, entre outros, para sociedade local (GODDARD; VALLANCE, 2010).

À medida que a internacionalização do ensino superior prossegue rapidamente, a comunidade universitária é afetada por essa nova configuração da globalização e todos os seus desafios. As universidades passam a desempenhar um papel fundamental na formação e consolidação das sociedades, alicerçadas em seu engajamento social, político e cultural e nas estratégias globais, nacionais e locais, promovendo o desenvolvimento da humanidade. As universidades precisam estar mais próximas das questões que envolvem suas cidades, suas regiões e seus países para poderem oferecer contribuições mais efetivas. Muito dos principais problemas enfrentados pela humanidade, como a destruição do meio ambiente, o aumento da desigualdade social, a violência que atravessa as fronteiras, a migração humanitária, entre outros, só podem ser resolvidos se 
forem debatidos em conjunto pela universidade e pela sociedade. Dessa cooperação local, amplia-se para uma cooperação mais global, entre países que trabalhem juntos, mediados pelas academias (NAIDOO, 2016).

A tendência de agir apenas em situação de crise pode impedir que as universidades e que os países reflitam com mais cuidado sobre o planejamento a longo prazo. A oportunidade de ajudar os estudantes deslocados de regiões problemáticas num momento de necessidade, bem como a de fomentar parcerias entre instituições e universidades no exterior, não deve ser negligenciada.

\section{CONCLUSÃO}

Procuramos atender ao objetivo de fazer uma reflexão crítica sobre o papel da universidade brasileira e o fenômeno atual da imigração a partir das ações de internacionalização da educação superior, no âmbito da responsabilidade social. Entendemos que tal desafio se traduz no compromisso em formar os estudantes, nacionais e estrangeiros, a partir de linguagens interculturais que permitam a sua comunicação em um mundo globalizado. Assim, os ambientes e espaços destinados à produção e socialização do conhecimento devem atender de forma concreta à realidade sociocultural nacional e refletir sobre a realidade internacional, possibilitando uma visão mais abrangente em questões tão relevantes.

A natureza interconectiva dos diferentes sistemas de mundos exige habilidades para se compreender os problemas, para se pesquisar e para implementar soluções que levem em conta essas conexões. O impacto das decisões desses indivíduos, formados nas universidades, tem potencialidade, ou seja, seu impacto pode ser sentido em outros sítios globais. São jovens que terão habilidades de prever, avaliar e realizar julgamentos étnicos que irão refletir em suas ações pessoais, coletivas e profissionais sob uma perspectiva mais global.

A internacionalização da universidade, sob o ponto de vista da responsabilidade social, está centrada na integração das dimensões internacional, intercultural e global aos processos de ensino e aprendizagem e à inserção de seus formandos no mercado de trabalho. Como universidade, podemos ajudar imigrantes e nacionais a compreenderem essas questões, melhorando o seu entendimento em relação às interações humanas, inclusive das ações que estão por trás da própria internacionalização da universidade. Os movimentos migratórios no século XXI, inclusive o experimentado no Brasil, são, principalmente, daqueles que foram obrigados a se deslocar.

Nesse contexto, apesar dos dispositivos supranacionais de proteção dos migrantes e de toda classe de refugiados, fundada no direito de migrar, permanecem as narrativas discriminatórias e classificatórias do estrangeiro como indesejado ou até inimigo em potencial. O setor universitário, tanto no Brasil como no mundo, tem sido chamado a responder a essa crise humanitária de imigração por todo o globo, consistindo em um dos novos desafios da humanidade neste século. As ações de internacionalização das universidades brasileiras precisam incluir os imigrantes, pois eles precisam ser encorajados a desenvolver relacionamentos, envolver-se na comunidade de forma a poderem contribuir para o desenvolvimento local. Tal inclusão passa pela boa acolhida, pela inclusão na educação superior, pela interação cultural e, finalmente, pela inserção do imigrante no trabalho de forma digna e útil à sociedade receptora. 
Ações voluntárias desenvolvidas por estudantes nacionais e/ou estrangeiros, além de propiciar o senso de responsabilidade social pessoal, ajudam-os a criar uma conexão mais profunda com suas comunidades por meio dos serviços prestados. Parte das ações apontadas neste estudo está sendo realizada por voluntários junto às universidades. Apesar das iniciativas louváveis dos programas mencionados ao longo deste estudo, há um potencial maior a ser explorado visando a resultados mais efetivos.

Os projetos desenvolvidos atualmente pelas universidades brasileiras, que trabalham diretamente questões envolvendo a internacionalização da universidade por meio da responsabilidade social, e que envolvem iniciativas no auxílio na assimilação do imigrante, ainda são poucos. Grande parte dos projetos existentes parte exclusivamente da universidade ou da institução com alguma parceria de associações da sociedade civil. A interação entre ente público, empresas, governos e a própria universidade ainda é muito baixa no enfrentamento desses problemas. Isso seria reflexo de não haver ainda uma compreensão clara por parte das universidades brasileiras, da sociedade e do Estado do sentido e dos benefícios das ações de internacionalização que envolvam a responsabilidade social. Identifica-se que há motivações econômicas, políticas, acadêmicas e socioculturais no suporte ao desenvolvimento econômico e tecnológico do país, mas, a indicação de como a internacionalização, a partir do desenvolvimento dessas motivações, poderia contribuir para o fortalecimento da sociedade local, envolvendo os imigrantes, é praticamente inexistente. Eis aqui o desafio a ser perseguido pelas universidades na consolidação da responsabilidade social voltada aos imigrantes: conseguir mediar eventuais conflitos e trabalhar pela inserção do imigrante no tecido social de forma digna e produtiva.

A retórica promovendo acomodação de imigrantes em situação de vulnerabilidade, com viés, muitas vezes, assistencialista, parece ecoar mais alto do que a real necessidade de se criar uma programação consistente para atender às suas necessidades de curto, médio e longo prazos. $O$ apelo para se integrar os imigrantes em situação de vulnerabilidade, sem realmente fornecer programas mais efetivos, considerados caros para serem abraçados somente pela universidade, trazem consigo o risco de se abandonar esses indivíduos à própria sorte, contribuindo para aumentar o sentimento de marginalização, levando-os a muitas frustrações.

As universidades brasileiras, e também as de outros países em desenvolvimento, precisam se abrir aos benefícios do multiculturalismo, reconstruindo suas economias por meio da inserção e integração dos imigrantes. Eles também podem contribuir para preencher as lacunas de habilidades e competências, ajudando a suprir as necessidades econômicas dos países receptores. Não se esquecendo ainda de que eles podem retornar para casa, contribuindo para o desenvolvimento de seus próprios países a partir do que vivenciaram e aprenderam na comunidade, no mercado e nas universidades brasileiras, ajudando com isso a construir um mundo mais estável e pacífico para as futuras gerações. Portanto, tal processo passa, necessariamente, por encarar o desafio de consolidar a cultura da responsabilidade social, pessoal e institucional na acolhida plena ao imigrante, passando necessariamente pela sua inserção social, pela sua inclusão no mundo universitário e no mundo do trabalho. 


\section{MIGRATORY MOVEMENTS AND INTERNATIONALIZATION OF HIGHER EDUCATION}

ABSTRACT: The article establishes a dialogue between the internationalization of higher education and the role of the university based on migratory movements. It aims to make a critical reflection on the role of the Brazilian university and the current phenomenon of immigration from the internationalization actions of higher education within the scope of social responsibility. The study is based on a qualitative and quantitative approach based on bibliographic readings and document analysis using scientific journals, books and legal documents. The results show the reflection of the role of the university as an institution with transformative power of people through the bias of international cooperation through integrative social actions.

KEYWORDS: Internacionalization. Human Mobility. Refugees. Social Responsability.

\section{MOVIMIENTOS MIGRATORIOS E INTERNACIONALIZACIÓN DE LA EDUCACIÓN SUPERIOR}

RESUMEN: El artículo establece el diálogo entre la internacionalización de la educación superior y el papel de la universidad a partir de los movimientos migratorios. Tiene como objetivo hacer una reflexión crítica sobre el papel de la universidad brasileña y el fenómeno actual de la inmigración a partir de las acciones de internacionalización de la educación superior, en el ámbito de la responsabilidad social. El estudio se basa en un enfoque cualitativo y cuantitativo basado en lecturas bibliográficas y análisis de documentos, utilizando revistas científicas, libros y documentos legales. Los resultados presentan una reflexión sobre el rol de la universidad como institución con el poder de transformar a las personas, a través de la cooperación internacional, a través de acciones sociales integradoras.

PALABRAS CLAVE: Internacionalización, Movilidad Humana, Refugiados, Responsabilidad Social.

\section{NOTA}

1) As razões voluntárias referem-se a uma decisão pessoal que, na maioria das vezes, se dá por melhores condições de vida, já que seus países de origem não lhes proporcionam isso. Esses imigrantes, ainda que com muita dificuldade, possuem alguma condição financeira. Já os involuntários são os que, por força da política, das guerras, das crises econômicas e humanitárias graves, são forçados a sair de seus países de origem sem nenhuma alternativa e, muitas vezes, sem nenhum recurso financeiro para se manterem. Nos dois casos a decisão de sair é sempre difícil.

\section{REFERÊNCIAS}

ACNUR. Refúgio em números $4^{\circ}$ edição. 2018a. Disponível em: https://www.acnur.org/portugues/wp-content/uploads/2019/07/Refugio-emnu\%CC\%81meros versa\%CC\%83o-23-de-julho-002.pdf. Acesso em: 14 jul. 2020. 
ACNUR. Relatório de atividades 2018. 2018b. Disponível em: https://www.acnur.org/portugues/wp-content/uploads/2018/09/Relat\%C3\%B3rioC\%C3\%A1tedra-S\%C3\%A9rgio-Vieira-de-Mello-2018 final.pdf. Acesso em: 15 jul. 2020.

ACNUR. Cátedra Sérgio Vieira de Mello. 2018c. Disponível em: https://www.acnur.org/portugues/catedra-sergio-vieira-de-mello/. Acesso em: 15 jul. 2020.

AMARAL, Ana Paula Martins; COSTA, Luiz Rosado. A (não) criminalização das migrações e políticas migratórias no Brasil: do Estatuto do Estrangeiro à nova Lei de Migração.

Revista Justiça do Direito, Passo Fundo. v. 31, n. 2, p. 208-228, 2017. Disponível em: https://doi.org/10.5335/rjd.v31i2.7147.

BAENINGER, Rosana .; PERES, Roberta. Migração de crise: a imigração haitiana para o Brasil. Revista Brasileira de Estatística e População, Belo Horizonte. v. 34, n. 1, p. 119 143, 2017. Disponível em: http://dx.doi.org/10.20947/S0102-3098a0017.

BRASIL. Lei no 13.445, de 24 de maio de 2017. Brasília, DF, 2017. Disponível em: http://www.planalto.gov.br/ccivil_03/_ato2015-2018/2017/lei/L13445.htm. Acesso em: 20 jul. 2020.

BRASIL. Lei n9.474, de 22 de julho de 1997. Brasília, DF, 1997. Define mecanismos para a implementação do Estatuto dos Refugiados de 1951, e determina outras providências. Disponível em:

http://www.planalto.gov.br/ccivil_03/LEIS/L9474.htm. Acesso em 23 jul. 2020.

BRASIL. Constituição da república federativa do Brasil de 1988. Brasília, DF, 1988. Disponível em: http://www.planalto.gov.br/ccivil_03/constituicao/constituicao.htm. Acesso em: 22 jul. 2020.

BEALL, Jol. Universities and their importance to nations and cities. In: STIASNY, Mary.; GORE, Tim. Edt. Going Global, Connecting Cultures, Forging futures. London UCL Education Pres, 2016.

BRUCE, Aaron.; LUEKER Evelyn.; WICK, David. The Future of Inequality in Mobility. In: COLON, Catherine.; GRISTWOOD, Anthony.; WOLLF, Michael. Borders, Mobility and Migration. London. CAPA Occassional Publication, v. 8, 2019.

CASTLES, Stephen. Twenty-first-century migration as a challenge to sociology. Journal of ethnic and migration studies, v. 33, n. 3, p. 351-371, 2007. Disponível em: https://www.tandfonline.com/doi/abs/10.1080/13691830701234491. Acesso em: 21 jul. 2020. 
ELLIOTT, Timothy. Lynn., Permanent Borders and Other Myths We Live By. Em COLON, Catherine.; GRISTWOOD, Anthony.; WOLLF, Michael. Borders, Mobility and Migration. London. CAPA Occassional Publication, v. 8, 2019.

FREGUGLIA, R. S.; MENEZES FILHO, N. A. (2012). Inter-regional wage differentials with individual heterogeneity: evidence from Brazil. Ann Reg Sci (2012) 49:17-34.

FREGUGLIA, R. S.; MENEZES-FILHO, N. A.; SOUZA, D. B. (2007). Diferenciais Salariais Interregionais, Interindustriais e Efeitos Fixos Individuais: Uma Análise a Partir de Minas Gerais. Estudos Econômicos, São Paulo, v. 37, n. 1, p. 129-150, jan.-mar. 2007.

GAY, Lorraine; MILLS, Geoffrey.; AIRASIAN, Peter. Educational research: competencies for analysis and applications. 9th ed. Columbus, Ohio: Pearson, 2009.

GIL, Antonio Carlos. Métodos e técnicas de pesquisa social. 6. ed. São Paulo: Atlas, 2008. $200 \mathrm{p}$.

GODDARD, John.; VALLANCE, Paul. Universities and regional development. In: PIKE, Rodriguez-Pose; TOMANEY, John. Handbook of Local and Regional Development. London: Routledge, 2010.

HUDZIK, John. Comprehensive Internationalization: from Concept to Action.

Washington: NAFSA Association of International Educators, 2011.

LAJUS, Fernando. Dinâmicas migratórias e internacionalização do ensino superior. Revista Sociologias Plurais, v. 5, n. 1, p. 321-342, 2019.

LEÃO, L. M.. Metodologia do estudo e pesquisa: facilitando a vida dos estudantes, professores e pesquisadores. Petrópolis, RJ: Vozes, 2016. 134 p.

LEE, E. S. (1980). Uma teoria sobre a migração. In: MOURA, H. A. (org). Migração interna: textos selecionados. Fortaleza: Banco do Nordeste do Brasil S/A, 1980.

KILLICK, DAVID. Developing the Global Student: higher education in an era of globalization. Londres, Routledge, 2015.

MARTINE, G. (1984). Os dados censitários sobre migrações internas: evolução e utilização. IV Encontro Nacional de Estudos Populacionais. Anais... ABEP, v. 2, Águas de São Pedro, 1984.

MARTINE, G. (1987). Migração e metropolização. São Paulo em Perspectiva, São Paulo, Fundação Seade, v. 1, n. 2, p. 28-31, jul./set. 1987.

MENEZES, Lourdes Meireles. Refúgio no Brasil do pós-Segunda Guerra: a Illha das Flores como representação do Paraíso. Revista Brasileira de Pesquisa (Auto)Biográfica, 
Salvador. v. 3, n. 7. p. 109-125, 2018. Disponível em:

http://revistas.uneb.br/index.php/rbpab/article/view/4339. Acesso em: 22 jul. 2020.

MINISTÉRIO DA JUSTICA E SEGURANCA PÚBLICA, Relatório Anual do Observatório das Migrações Internacionais - OBMigra 2019. Disponível em:

https://www.justica.gov.br/news/collective-nitf-content-1566502830.29 Acesso em: 17 set. 2020.

MIRANDA, J. A. A; MISTURA, A. Globalização e a Nova Lei de Imigração: uma análise da evolução na lida com o imigrante no Brasil. Revista Direito e Liberdade. v. 20, p. 149173, 2018.

MOROSINI, Marilia. Dossiê: Internacionalização da Educação Superior. Revista Educação, Porto Alegre, v. 40, n. 3, p. 288-292, 2017.

NAIDOO, Rajani. Beyond national competition: transnational higher education for global well-being. In: STIASNY, Mari.; GORE, Tim Edt. Going Global, Conecting Cultures,

Forging futures. London UCL Education Pres, 2016.

ORTEGA, Lourdes. Global Perspective Through Local Interactions, In: COLON, Catherine.; GRISTWOOD, Anthony.; WOLLF, Michael. Globalization, Civilization, and their Discontents. London. CAPA Occassional Publication, v. 7, 2018.

OECD. Territorial Reviews: Cape Town, South Africa. Paris: OECD, 2007.

ONU. Mundo tem 232 milhões de migrantes internacionais, calcula ONU, 2013. Disponível em: https://nacoesunidas.org/mundo-tem-232-milhoes-de-migrantesinternacionais-calcula-onu/. Acesso em: 23 jul. 2020.

PATARRA, Neide Lopes. Migrações internacionais de e para o Brasil contemporâneo: volumes, fluxos, significados e políticas. Revista São Paulo em Perspectiva, São Paulo. v. 19, n. 3, p. 23-33, 2005. Disponível em: http://www.scielo.br/scielo.php?script=sci arttext\&pid=S0102-

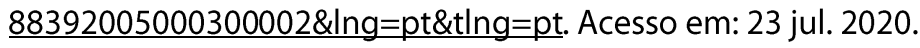

REIS, Rosana Rocha. A política do Brasil para as migrações internacionais. Revista Contexto Internacional, Rio de Janeiro. v. 33, n. 1, p. 47-69, 2011. Disponível em http://www.scielo.br/scielo.php?script=sci arttext\&pid=S0102-85292011000100003. Acesso em: 24 jul. 2020.

SERRICELLA, Giulianna Silva. Globalização e Refúgio - os refugiados congoleses na cidade do Rio De Janeiro como exemplo dessa relação complexa. Dissertação (Mestrado 
MIRANDA, J. A. A. de; FOSSATI, P

em Geografia) - Programa de Pós-graduação em Geografia, PUC-Rio, Rio de Janeiro, 157f., 2016.

STREITWIESER, Bernhard; MILLER-IDRISS, Cynthia; WIT, Hans de. Higher Education`s Response to the European Refugee Crisis, In: WIT, Hans de; GARCEL-ÁVILA, Jocelyne; JONES, Elspeth; JOOSTE, Nico. The Globalization of Internationalization: emerging voices and perspectives. London, Routledge, 2017.

TODARO, M. P. (1980). A migração de mão de obra e o desemprego urbano em países desenvolvidos. In: MOURA, H. A. (org). Migração interna: textos selecionados. Fortaleza: Banco do Nordeste do Brasil S/A, 1980.

UEBEL, Roberto Rodolfo Georg; RÜCKERT, Aldomar Arnaldo. Aspectos gerais da dinâmica imigratória no Brasil no século XXI. Revista Franco-brasileira de Geografia, Nova Friburgo, n. 31 2017. Disponível em:

https://journals.openedition.org/confins/11905. Acesso em: 23 jul. 2020.

WIT, Hans de.; ALTBACH, Philips. The Syrian refugee crisis. What can universities do? University World News, 2015. Disponivel em: https://www.universityworldnews.com/post.php?story=20150918113842639. Acesso em: 05 ago. 2019.

WHALEN, Brian. Surveying Borders as Concept and Tool in Education Abroad. In: COLON, Catherine.; GRISTWOOD, Anthony.; WOLLF, Michael. Borders, Mobility and Migration. London. CAPA Occassional Publication, v. 8, 2019.

WOOD, C. H. (1982). Equilibrium and historical structural perspectives on migration. International Migration Review, v. 16, no 2, 1982.

WOOLF, Michael. What Brought you here? Em COLON, Catherine.; GRISTWOOD, Anthony.; WOLLF, Michael. Borders, Mobility and Migration. London. CAPA Occassional Publication, v. 8, 2019.

\footnotetext{
José Alberto Antunes de Miranda: Possui graduação em Direito pela Universidade do Vale do Rio dos Sinos (1996), Especialização em Integração e Mercosul pela UFRGS (1999), Mestrado em Relações Internacionais pela Universidade Federal do Rio Grande do Sul (2004) e Doutorado em Estudos Estratégicos Internacionais pela UFRGS (2012). Atualmente é Assessor de Assuntos Interinstitucionais e Internacionais e professor permanente do Programa de Pós-graduacao em Direito e Sociedade além de integrar o corpo docente do Curso de Relações Internacionais da Universidade La Salle. Também é professor visitante ilustre da Universidade Católica de Trujillo no Peru.

Orcid: https://orcid.org/0000-0002-5338-4728

E-mail: jose.miranda@unilasalle.edu.br
} 
Paulo Fossati: Doutor em Educação (aprovado com louvor) pela Pontifícia Universidade Católica do Rio Grande do Sul - PUCRS (2009) e Pós-Doutorado em Ciências da Educação e pesquisador associado da Universidade do Algarve (2011). Possui graduação em Filosofia (1993) e em Psicologia (1997) pela Universidade do Vale do Rio dos Sinos. Especialista em Administração Escolar pela Unilasalle Canoas/RS (1999) e mestrado em Psicologia Social e Institucional pela Universidade Federal do Rio Grande do Sul (2002). Consultor Ad Hoc do CNPq. Professor e pesquisador do Programa de Pós-Graduação em Educação da Universidade La Salle - RS, e Reitor desta Universidade.

Orcid: https://orcid.org/0000-0002-9767-5674

E-mail: paulo.fossatti@unilasalle.edu.br

Este periódico utiliza a licença Creative Commons Attribution 3.0, para periódicos de acesso aberto (Open Archives Iniciative - OAI). 